\title{
Pd/FER vs Pd/SSZ-13 Passive NOx Adsorbers: Adsorbate-controlled Location of Atomically Dispersed Pd(II) in FER Determines High Activity and Stability
}

\author{
Konstantin Khivantsev, ${ }^{\text {\&a* }}$ Xinyi Wei, ${ }^{\text {\&b* }}{ }^{\star}$ Libor Kovarik, ${ }^{a}$ Nicholas R. Jaegers, ${ }^{a}$ Eric D. Walter, ${ }^{a}$ \\ Pascaline Tran, ${ }^{b}$ Yong Wang ${ }^{a, c}$ and János Szanyi ${ }^{a *}$
}
Institute for Integrated Catalysis
Pacific Northwest National Laboratory
Richland, WA 99352 USA
[b] Dr. Xinyi Wei, Dr. Pascaline Tran
Environmental Catalysis Research Division, BASF
Iselin, NJ 08830 USA
[c] Dr. Yong Wang, Voiland School of Chemical Engineering and Bioengineering
Washington State University
Pullman, WA 99164 USA

[a] Dr. Konstantin Khivantsev, Dr. Libor Kovarik, Dr. Nicholas R. Jaegers, Dr. Yong Wang, Dr. Janos Szanyi,

Emails (correspondence to): Konstantin.Khivantsev@pnnl.gov, Xinyi.Wei@basf.com, Janos.Szanyi@pnnl.gov,

Supporting information for this article is given via a link at the end of the document

\begin{abstract}
Pd-loaded FER and SSZ-13 zeolites as low-temperature passive NOx adsorbers (PNA) are compared under practically relevant conditions. Vehicle cold-start exposes the material to $\mathrm{CO}$ under a range of concentrations, necessitating a systematic exploration of the effect of $\mathrm{CO}$ on the performance of isolated $\mathrm{Pd}$ ions for PNA. NO release temperature of both adsorbers decreases gradually with the increase of $\mathrm{CO}$ concentration from a few hundred to a few thousand ppm. This beneficial effect results from local nano"hot spots" formation during CO oxidation. Dissimilar to Pd/SSZ-13, increasing the $\mathrm{CO}$ concentration above $\sim 1,000 \mathrm{ppm}$ improves the NOx storage significantly for $\mathrm{Pd} / \mathrm{FER}$, attributed to the presence of a $\mathrm{Pd}$ ions in FER $\mathrm{y}$-site that is shielded from $\mathrm{NO}_{x}$. $\mathrm{CO}$ mobilizes this $\mathrm{Pd}$ atom to the $\mathrm{NO}_{x}$ accessible position where it becomes active for PNA. This behavior explains the very high resistance of $P d / F E R$ to hydrothermal aging: Pd/FER materials survive hydrothermal aging at $800^{\circ} \mathrm{C}$ in $10 \% \mathrm{H}_{2} \mathrm{O}$ vapor for 16 hours with no deterioration in NOx uptake/release behavior. Thus, by allocating $\mathrm{Pd}$ ions to the specific microporous pockets in FER, we have produced very hydrothermally stable and active PNA materials with immediate practical applications.
\end{abstract}

\section{Introduction}

Improving air quality is one of the grand challenges in our society [1-3]. Since exhaust from internal combustion engines produces the majority of toxic NOx emissions, there is a continuing need to improve their effectiveness. Most recently, the ammonia selective catalytic reduction (SCR) technology which was first discovered in the 1970s [29] for Cu/Y zeolites was proposed for Cu/SSZ-13 [30] and later implemented by BASF on a large scale and described in the literature [4,5]. Such technology successfully removes NOx [4,5] at temperatures above $200^{\circ} \mathrm{C}$, relying on a sacrificial ammonia source (urea), with copper ions dispersed in small-pore SSZ-13 zeolite being the catalytically active species. However, at low temperatures $\left(<150^{\circ} \mathrm{C}\right)$, during vehicle cold start for example, known catalysts are incapable of performing this challenging reaction effectively. Furthermore, ammonia cannot be delivered successfully to the catalyst at temperatures $<180^{\circ} \mathrm{C}$ when urea is used as the source of ammonia. In order to address the low-temperature cold start problem, $\mathrm{Pd} /$ zeolite materials were introduced as passive $\mathrm{NO}_{x}$ adsorbers (PNA) [6-22]. Conceptually, $\mathrm{NO}_{x}$ is adsorbed at low temperature and released at temperatures when Cu/SSZ-13 is active for SCR $\left(200^{\circ} \mathrm{C}\right.$ and higher). As it was recently shown, the active sites in these $\mathrm{Pd}$-containing materials are isolated $\mathrm{Pd}$ ions located in the micropores of various zeolites [6-20]. Various structure-adsorption property relationships have been revealed for a range of $\mathrm{Pd} /$ zeolite materials (SSZ-13, BEA, MFI, MWW, SSZ-39) and guidelines for the preparation of highloadings of atomically dispersed materials have been disclosed [6-22, 24-27]. More recently, FER materials were used to support $\mathrm{Pd}$ and their PNA performance has been evaluated [21,22]. Despite this success, there remains a formidable challenge to produce materials that 1 ) retain hydrothermal stability up to $800^{\circ} \mathrm{C} ; 800^{\circ} \mathrm{C}$ hydrothermal aging is an expedited aging protocol to simulate end of useful life for a material (such a benchmark would circumvent potential degradation stimulated by diesel particulate filter (DPF) regeneration since maximum exhaust gas temperatures reach up to $\sim 700^{\circ} \mathrm{C}$ during this process) 2) perform well in the presence of elevated levels of $\mathrm{CO}$ during cold start from a few hundred to a few thousand ppm, and 3) exhibit excellent performance during consecutive PNA cycles and be regenerable. Such materials have not been prepared before. Herein, we compare the performance and stability of $\mathrm{Pd} / \mathrm{FER}$ and $\mathrm{Pd} / \mathrm{SSZ}-13$ and derive novel structure-adsorption property relationships for these materials. $\mathrm{Pd} / \mathrm{FER}$ contains a specific isolated $\mathrm{Pd}$ site in the FER micropore that is inaccessible to adsorbates such as NOx, and water. This site is activated and moved into a more accessible position in the presence of higher $\mathrm{CO}$ concentrations (>500 ppm) and produces an excellent PNA material with a capacity comparable to the best SSZ-13 materials. Moreover, higher CO partial pressures lead to the release of $\mathrm{NO}_{\mathrm{x}}$ in close to the ideal temperature range of $\sim 200-300{ }^{\circ} \mathrm{C}$ (depending on the effectiveness of SCR catalyst and the gap between the PNA and SCR zones) as a result of local nano-"hot spots" formation due to CO oxidation. 


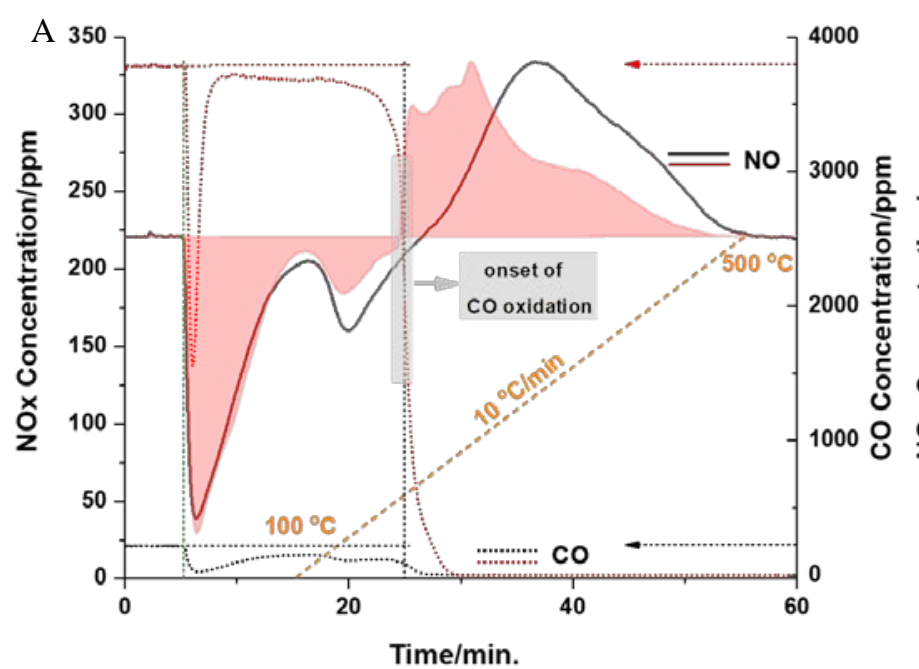

B

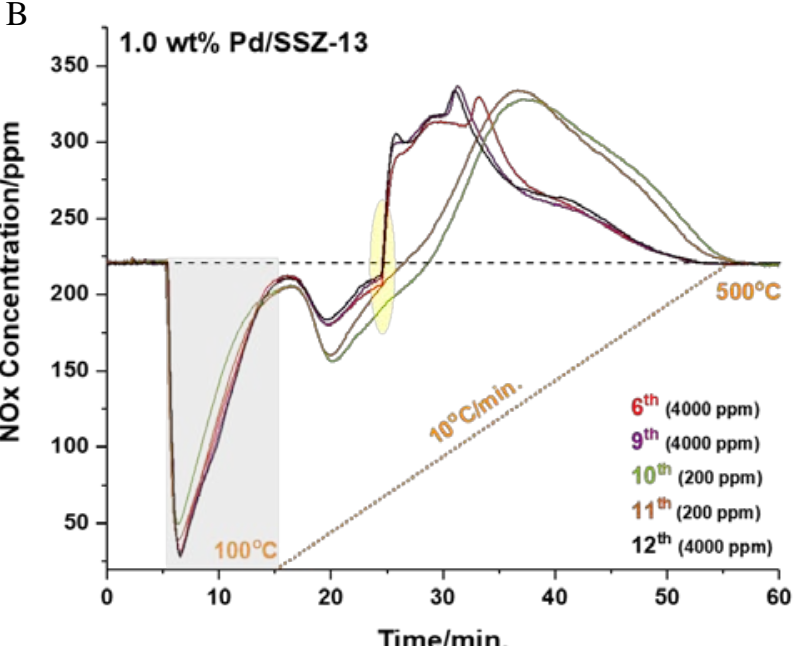

Figure 1. A. NOx (solid line) and CO concentration (dashed line) profiles for a 1 wt\% Pd/SSZ-13 (Si/Al 6) PNA in the presence of 200 ppm (black) and 4,000 ppm CO (red). Th eorange line represents the temperature profile. [Nox uptake: at $100^{\circ} \mathrm{C}$ for $10 \mathrm{~min}$ in $220 \mathrm{ppm} \mathrm{NOx}\left(200 \mathrm{ppm} N \mathrm{NO}\right.$ and $20 \mathrm{ppm} \mathrm{NO}$ ), 200/4000 ppm CO, 14\% O , $3 \% \mathrm{H}_{2} \mathrm{O}$, balanced with $\mathrm{N}_{2}$ at a flow rate of $300 \mathrm{sccm}$.] B. Comparison of PNA performance of the same material during repeated cycles with varying levels (200 and 4,000 ppm) of CO in the feed.

Through a series of detailed adsorption-desorption experiments it is shown that the $\mathrm{NO}_{\mathrm{x}}$ release temperature coincides with the onset of $\mathrm{CO}$ oxidation. We show the excellent performance of these materials under practically relevant conditions. Moreover, due to the presence of a specific Pd site in the FER micropores not accessible to water during hydrothermal aging at $800^{\circ} \mathrm{C}$ (and even $850{ }^{\circ} \mathrm{C}$ ) in $10 \% \mathrm{H}_{2} \mathrm{O} / \mathrm{O}_{2} / \mathrm{N}_{2}$ mix for 16 hours, no changes in the adsorption of $\mathrm{NO}_{\mathrm{x}}$ occur, a feature that has not been previously achieved with any PNA material [6-19]. Although previously Pd/SSZ-39 [14] showed stability of NOx uptake after aging at $800^{\circ} \mathrm{C}$, the NOx release profile broadened and shifted to higher temperatures which was not desirable (at CO levels $\sim 250$ ppm in [14]).

\section{Results and Discussion}

We have previously described structure-catalytic property relationships for $\mathrm{Pd} / \mathrm{SSZ}-13$ with $\mathrm{Si} / \mathrm{Al} \sim 6[7,9]$. In the dry state this material contains predominantly super-electrophilic $\mathrm{Pd}^{+2}$ sites held electrostatically by 2 oxygens associated with framework Al atoms (see HAADF-STEM images and FTIR during CO adsorption in Figs. S1,2). In the previous studies [6-19], CO levels around $200-250 \mathrm{ppm}$ were used during NOx adsorption tests. However, there is continuous interest to test the performance in the presence of higher $\mathrm{CO}$ levels that are most relevant during cold start. Fig.1A shows the comparison of the PNA performance of a $1 w t \% \mathrm{Pd} / \mathrm{SSZ}-13$ (Si/Al 6) material with 200 and 4,000 ppm $\mathrm{CO}$ at a GHSV $\sim 150 \mathrm{~L} / \mathrm{g}^{*} \mathrm{hr}$. We observe that increase in CO level does not change the NOx uptake. In contrast, the NOx release temperature changes significantly to lower temperature in the presence of higher concentrations of $\mathrm{CO}$. This seems to coincide with the onset of $\mathrm{CO}$ oxidation activity. Since $\mathrm{CO}$ oxidation is highly exothermic, such $\mathrm{CO}$ concentrations create localized nanohotspots (during $\mathrm{CO}$ oxidation) that drive NOx off at lower temperatures (detailed below during discussion regarding $\mathrm{Pd} / \mathrm{FER}$ ). This phenomenon is advantageous since during regular transient Federal Test Procedure (FTP) cycles the highest necessitating NOx release below $450^{\circ} \mathrm{C}$. Ideally, all NOx would be released at temperature below $\sim 400^{\circ} \mathrm{C}$. Fig. $1 \mathrm{~B}$ shows consecutive NOx uptake/release cycles on this material with varying levels of $\mathrm{CO}$ in the gas stream: the performance of $\mathrm{Pd} / \mathrm{SSZ}-13$ remains stable as long as all NOx is driven off from the material during temperature elevation. During the 12 consecutive cycles at $\mathrm{CO}$ concentration of either $\sim 200$ or 4,000 $\mathrm{ppm}$, the NOx uptake and release remained constant, irrespective of the CO level. In situ EPR studies of $\mathrm{Pd}(\mathrm{II}) / \mathrm{SSZ}-13$ under relevant flow conditions in the presence of $1000 \mathrm{ppm} \mathrm{CO}$ demonstrated the absence of the reduction of $\mathrm{Pd}(\mathrm{II})$ to $\mathrm{Pd}(\mathrm{I})$ or $\mathrm{Pd}(0)$ (Fig. S3), confirming the high stability of $\mathrm{Pd}(\mathrm{II}) / 2 \mathrm{Al}$ sites in SSZ-13.

$\mathrm{Pd} / \mathrm{FER}$ has received much less attention in the literature than other zeolites such as SSZ-13, BEA [6-14], and more recently SSZ-39, MFI and MWW [11,14]. Lietti and co-workers very recently described the first example of utilizing Pd/FER system for NOx adsorption [21]. We utilize this system with Pd supported on $\mathrm{H}-\mathrm{FER}$ with Si/Al ratio $\sim 10$ and with a Pd loading of $\sim 1.8 \mathrm{wt} \%$. [7,9] HAADF-STEM images for $1.8 \% \mathrm{Pd} / \mathrm{H}-\mathrm{FER}$ show highly crystalline FER material with $\mathrm{Pd}$ dispersed inside the pores as well as some ultra-small PdO clusters $(<1 \mathrm{~nm})$ decorating the periphery of the crystals (Fig. 2A,B, Fig. S4, consistent with FTIR data during $\mathrm{CO}$ adsorption showing a minor fraction of $\mathrm{CO}$ adsorbed on metallic Pd clusters below $<2090 \mathrm{~cm}^{-1}$ in Fig. 2C)), similar to that observed for $\mathrm{Pd} / \mathrm{SSZ}-13$ with Si/Al ratio $\sim 10-12$ [Figs. S5]. We chose to calcine the sample at $800^{\circ} \mathrm{C}$ in oxygen because this treatment apparently produces the most active materials (Fig. S6). In situ infrared spectra employing $\mathrm{CO}$ probe molecules were collected to characterize the adsorption sites present in the fresh (pre-calcined in $\mathrm{O}_{2}$ in the FTIR cell) and $800^{\circ} \mathrm{C}$-calcined (in the presence of oxygen) materials (Fig. 2C). Substantial changes in the distribution of $\mathrm{Pd}$ species were observed as a result of calcination. Specifically, the freshlycalcined sample contains bands corresponding to mainly $\mathrm{CO}$ adsorbed on $[\mathrm{Pd}(\mathrm{II})(\mathrm{OH})]^{+}\left(\right.$at $2147-2132 \mathrm{~cm}^{-1}$ ) complexes [9] are 

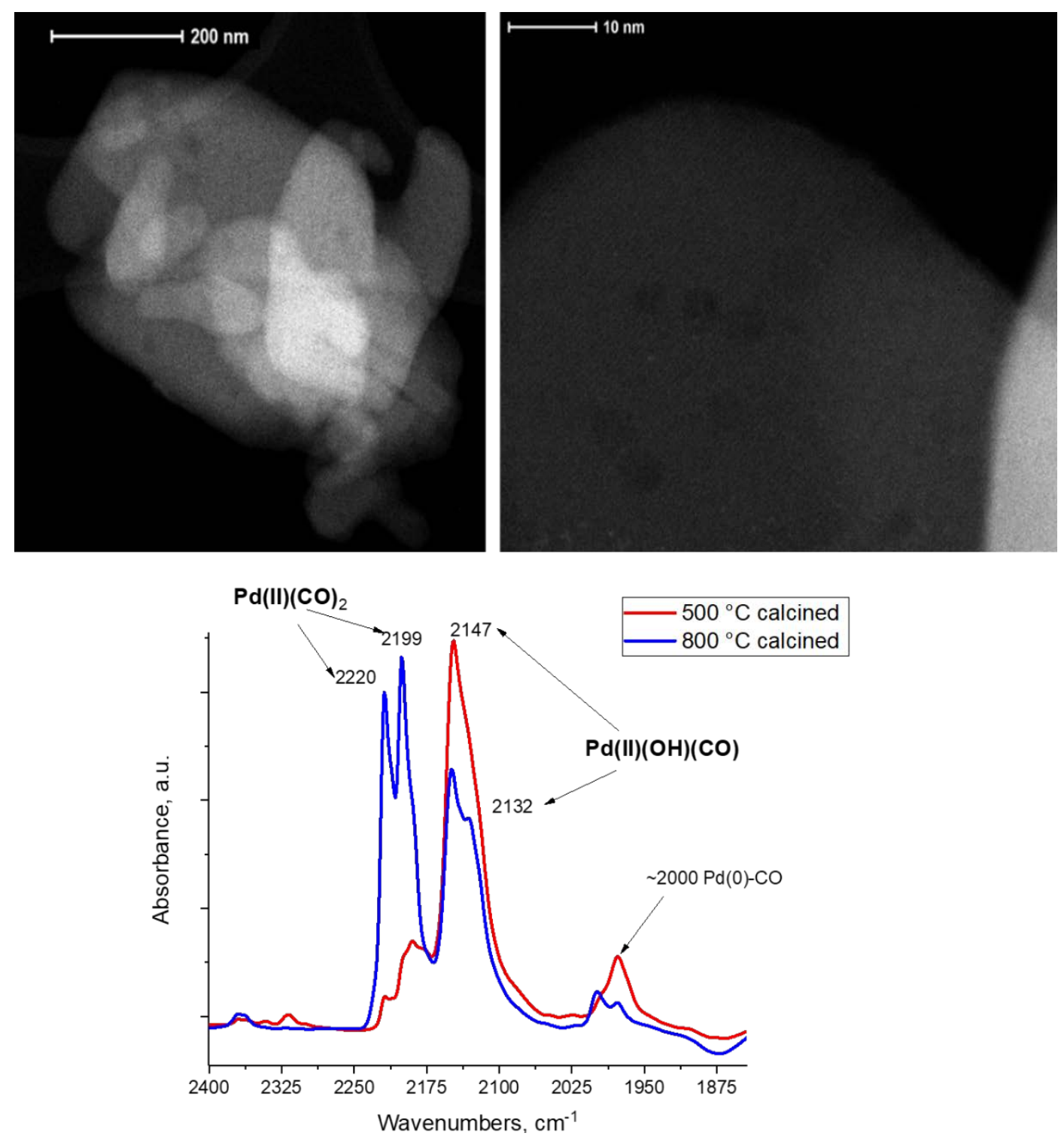

Figure 2. A. Low-magnification HAADF-STEM image of 1.8 wt\% Pd/FER. B. High-magnification HAADF-STEM image of 1.8 Pd/FER. C. FTIR data during CO adsorption (10 Torrs) on in-situ calcined (in simulated air in the IR cell) at $500{ }^{\circ} \mathrm{C}$ (red spectrum) and $800{ }^{\circ} \mathrm{C}$ in-situ calcined (blue spectrum) 1.8 wt\% Pd/FER sample.

almost exclusively present in the fresh sample. After $800^{\circ} \mathrm{C}$ in-situ calcination in air all the spectral features belonging to $\mathrm{CO}$ adsorbed undergo substantial changes (re-distribution). The intensities of the $\mathrm{Pd}(\mathrm{OH})$-bound $\mathrm{CO}$ features decreased while the bands at 2220 and $2199 \mathrm{~cm}^{-1}$, corresponding to CO adsorbed on $\mathrm{Pd}^{+2} / 2 \mathrm{Al}$ ions $\left(2,220\right.$ and $\left.2,199 \mathrm{~cm}^{-1}\right)[7,9]$ increased at their expense. These vibrational features are very similar to those we studied in details on $\mathrm{Pd} / \mathrm{SSZ}-13$, and assigned them to a $\mathrm{Pd}(\mathrm{II})(\mathrm{CO})_{2}$ complex formed on super electrophilic $\mathrm{Pd}(\mathrm{II})$ ions in the zeolite. These results indicate that $\mathrm{Pd}$ cations can diffuse and re-distribute in the micropores during calcination at $800^{\circ} \mathrm{C}$, producing more active sites for NO adsorption (Fig. S6). Such peculiar behavior has been previously observed during in-situ Rietveld refinement studies [31] for divalent metal cations in FER zeolite. More specifically, it was suggested that 3 specific sites can accommodate divalent $(\mathrm{Ni}, \mathrm{Mg}, \mathrm{Co})$ cations: the $\alpha$-site is located at the center of the 6-ring separating two ferrierite cages, the $\beta$-site is coordinated to the walls of the 10-MR channels while the $\gamma$-site is located inside the ferrierite cage, in a boat-shaped position [31]. The $y$-site is the most sterically-crowded site in FER. Clearly, the most accessible sites are filled by $\operatorname{Pd}(\mathrm{II})$ ions first, and their IR signatures correspond predominantly to $\mathrm{Pd}(\mathrm{II})(\mathrm{OH})(\mathrm{CO})$ species held by $1 \mathrm{Al}$ atom (in such positions that are filled by $\mathrm{Pd}$ $\mathrm{OH}$ first, obviously, no sites with $2 \mathrm{Al}$ atoms in close proximity are available, otherwise a $\mathrm{Pd}(\mathrm{II}) / 2 \mathrm{Al}$ site would form instead of $\mathrm{Pd}(\mathrm{II})$ $\mathrm{OH}$ because $\mathrm{Pd}(\mathrm{II}) / 2 \mathrm{Al}$ is more thermodynamically stable than $\mathrm{Pd}(\mathrm{II})(\mathrm{OH}) / 1 \mathrm{Al}$ site $[7,9])$. Upon heating, $\mathrm{Pd}$ cations diffuse and start to occupy the less accessible positions, which, however, offer a different $\mathrm{Al}$ distribution that allows $\mathrm{Pd}(\mathrm{II})$ to form thermodynamically preferred $\mathrm{Pd}(\mathrm{II}) / 2 \mathrm{Al}$ ions. These FTIR findings provide the clearest spectroscopic evidence of $\mathrm{Pd}(\mathrm{II})$ ions movement and re-distribution in FER upon heating at $800^{\circ} \mathrm{C}$, showing a direct evidence of the processes previously suggested on the basis of Rietveld refinement studies. These data also show that Al distribution within different sites in FER is not random, with Al pairs mostly concentrated in more sterically crowded locations (in the vicinity of $\mathrm{y}$-site). 
Based on the NOx/Pd ratio during PNA studies of these materials, the majority $(90 \%)$ of $P d$ is atomically dispersed and the NOx/Pd ratio is $>0.9$ for $4,000 \mathrm{ppm} \mathrm{CO}$ in the feed. Fig. $3 \mathrm{~A}$ shows the performance of this material in the presence of $\sim 200$ and $4,000 \mathrm{ppm} \mathrm{CO}$. A very significant shift of the NOx release is observed to lower temperatures with a sharp release of NOx at $\sim 200^{\circ} \mathrm{C}$ and slightly broader feature at $\sim 250^{\circ} \mathrm{C}$. Fig. 3B depicts $\mathrm{NO}_{x}$ and $\mathrm{CO}$ profiles simultaneously during a NOx uptake/release cycle in the presence of $4000 \mathrm{ppm} \mathrm{CO}$. At $200 \mathrm{ppm} \mathrm{NO}$ concentration at the inlet, the $\mathrm{NO}$ release is completed at $\sim 350^{\circ} \mathrm{C}$ with a maximum around $300^{\circ} \mathrm{C}$, which is more attractive than $\mathrm{Pd} / \mathrm{SSZ}-13$. In the presence of 4,000 ppm CO the absorbed amount of $\mathrm{NO}_{x}$ increases significantly ( $\sim 2$ times) in comparison to that in the presence of $200 \mathrm{ppm} \mathrm{CO}$. This behavior is completely different from that observed for $\mathrm{Pd} / \mathrm{SSZ}-13$ where the NOx uptake was not affected by the $\mathrm{CO}$ concentration in the gas stream (Fig. 1). Moreover, additional tests with model Pd/FER (Figures S7-S9) have shown that even $\sim 1,000 \mathrm{ppm}$ CO was sufficient to maximize NOx adsorption capacity. This is advantageous since cold-start $\left(\sim 100^{\circ} \mathrm{C}\right)$ exposes the material to high concentrations of $\mathrm{CO}$. We have previously observed the selective formation of a mixed carbonyl nitrosyl complex [Pd(II)(CO)(NO)] in Pd/SSZ-13 and it was confirmed that the formation of this mixed-ligand complex was responsible for the promoting mechanism $\mathrm{CO}$ has on NOx uptake in Pd/SSZ-13 and other Pd-containing materials [7-10, 13, 23]. Increasing $C O$ levels higher than 200 ppm in the case of $\mathrm{Pd} / \mathrm{SSZ}-13(\mathrm{Si} / \mathrm{Al}=6)$ does not increase NOx uptake since maximum adsorption capacity was already achieved with NO/Pd ration near unity at $\mathrm{Pd}$ loadings up to $1.9 \mathrm{wt} \%$. However, the phenomenon observed for Pd/FER is notably different. Two possible explanations for the significant promotion of $\mathrm{NO}_{x}$ uptake by elevated CO levels (>1000 ppm), are presented next. First, the $100^{\circ} \mathrm{C}$, we do not observe significant redispersion of these small PdO clusters based on microscopy (Fig. S9); moreover, such clusters are not present in significant amounts. Alternatively, some isolated $\mathrm{Pd}(\mathrm{II})$ ions located inside the micropores of FER are inaccessible for NOx adsorption. However, $\mathrm{CO}$, due to its strong interaction with $\mathrm{Pd}(\mathrm{II})$, is able to move those $\mathrm{Pd}$ ions to a more accessible location from their confined $\mathrm{y}$-position where they become available for NOx adsorption. This unique behavior highlights a potential mechanism to control the location of a charge compensating cation by one adsorbate in order to enhance the adsorption of another adsorbate. Such a notable attribute has an immediate application for synthesizing practically relevant materials which often need to sustain harsh hydrothermal aging at $800^{\circ} \mathrm{C}$ in $10 \% \mathrm{H}_{2} \mathrm{O}$ /air mixture for extended period. In the engine, during DPF regeneration and overload the exhaust gas stream reaches temperatures sometimes up to $800{ }^{\circ} \mathrm{C}$. Thus, practically viable materials must survive hydrothermal aging without much deterioration of adsorption capacity and similar (or better) adsorption-desorption behavior as the materials before aging. It was previously shown that the best $\mathrm{Pd} / \mathrm{SSZ}-13$ materials [12] lose $\sim 10-15 \%$ of atomically dispersed Pd after $\mathrm{HTA}$ at $750^{\circ} \mathrm{C}$ in $10 \% \mathrm{H}_{2} \mathrm{O}$ /air mix for 16 hours. $\mathrm{Pd}(\mathrm{II})$ ions are removed from their cationic positions by water hydrolysis (as hydrated mobile $\mathrm{Pd}(\mathrm{II})(\mathrm{OH})_{2}$ species) and then agglomerate into large $\mathrm{PdO}$ nanoparticles on the external SSZ-13 surface which are not easily redispersed by either oxidative heat or $\mathrm{NO} / \mathrm{O}_{2}$ treatment due to their large size [12]. Pd supported on large defect-free H-BEA crystals has shown high resistance to agglomeration at $750^{\circ} \mathrm{C}$ in $10 \% \mathrm{H}_{2} \mathrm{O} /$ air [8]. More recently, $\mathrm{Pd} / \mathrm{SSZ}-39$ was utilized for PNA and even though $\mathrm{H}-\mathrm{SSZ}-39$ crystals survived hydrothermal aging up to $1,000^{\circ} \mathrm{C}$ in $10 \% \mathrm{H}_{2} \mathrm{O}$ vapor, $\mathrm{Pd} / \mathrm{SSZ}-39$ started to show signs of NOx uptake deterioration after HTA above $815^{\circ} \mathrm{C}$ [14].
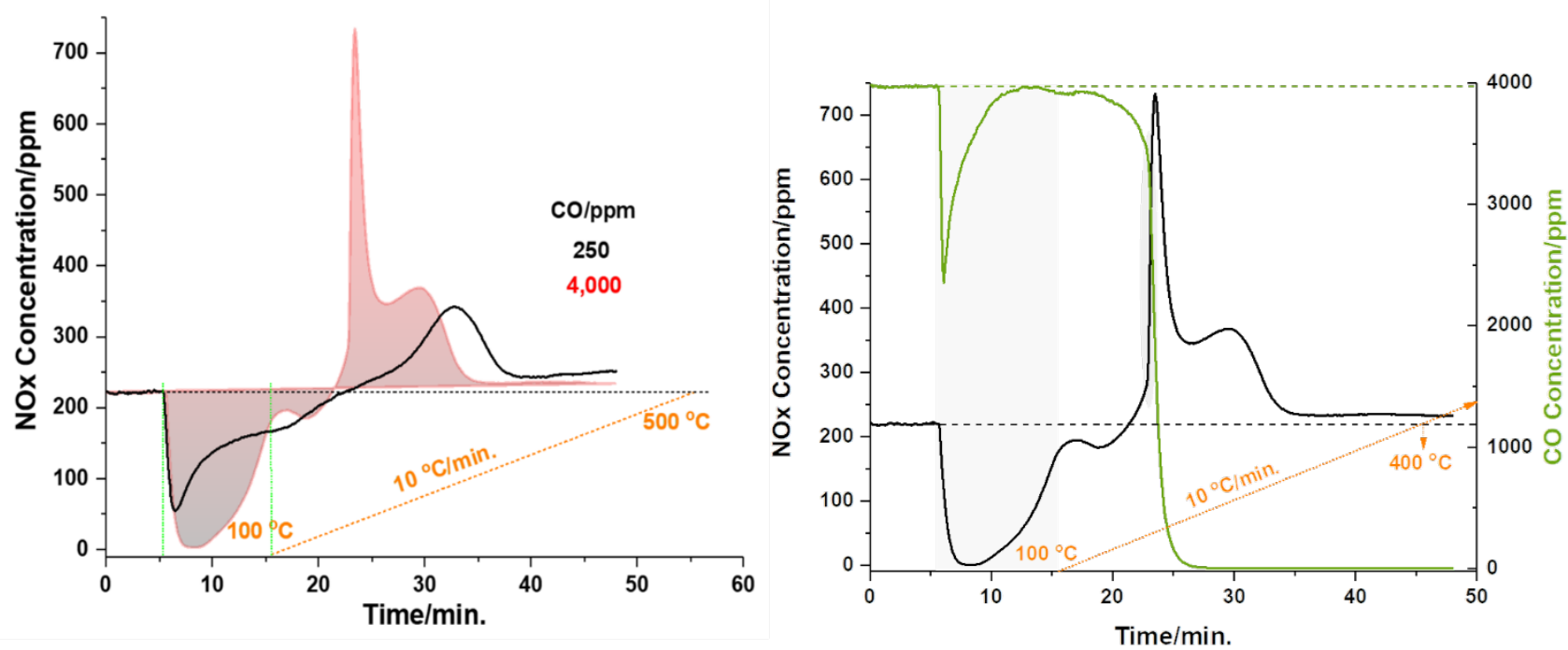

Figure 3. A. PNA performance of $1.8 \mathrm{wt} \% \mathrm{Pd} / \mathrm{FER}$ (Si/Al $\sim 10$ ) (sample was hydrothermally aged at $\left.800^{\circ} \mathrm{C}\right)[220 \mathrm{ppm}$ NOx (200 ppm NO and 20 ppm NO 2$), 200 / 4000$ ppm CO, 14\% O , $3 \% \mathrm{H}_{2} \mathrm{O}$, balanced with $\mathrm{N}_{2}$ at a flow rate of 300 sccm.] NOx uptakes for the 250 ppm and 4,000 ppm CO experiments were $\sim 0.45$ and $\sim 0.9$ NOx/Pd, respectively. B. Simultaneous $\mathrm{CO}$ and NOx profiles during PNA in the presence of $\sim 4,000 \mathrm{ppm} \mathrm{CO}$.

redispersion of small $\mathrm{PdO}$ particles and the formation of $\mathrm{Pd}(\mathrm{II})(\mathrm{NO})(\mathrm{CO})$ mixed-ligand complex may be easier in the presence of high $\mathrm{CO}$ concentrations in the $\mathrm{CO}+\mathrm{NO}$ mixture. However, the amount of Pd present as small clusters outside the zeolite should be much larger if this were the case. Moreover, when the sample is exposed to a $\mathrm{CO}+\mathrm{NO}+\mathrm{O}_{2}+\mathrm{H}_{2} \mathrm{O}+\mathrm{N}_{2}$ mixture at
Furthermore, after HTA the $\mathrm{NO}_{x}$ release profile broadened and was extended to temperatures above $>400^{\circ} \mathrm{C}$ which is undesirable. Contrary to those, $1.8 \mathrm{wt} \% \mathrm{Pd} / \mathrm{FER}$ material, after hydrothermal aging at $800^{\circ} \mathrm{C}$ in $10 \% \mathrm{H}_{2} \mathrm{O}$ vapor, showed no signs of deterioration [Fig. 3, S10]. This suggests that $\mathrm{Pd}$ ions indeed remain stabilized in their framework positions and are not 
accessible for water to hydrolyze them. Even after $850^{\circ} \mathrm{C}$ HTA for 16 hours $50 \%$ of the original $\mathrm{NO}_{x}$ capacity, associated with those "hidden" Pd locations, remained [Fig. S10].

We suggested earlier in this study that the reason for the shifting NOx release profile to lower temperatures resulted from the exothermicity of $\mathrm{CO}$ oxidation. In the presence of elevated $\mathrm{CO}$ levels (>1,000 ppm), CO oxidation may produce enough heat to create local over-heating and, consequently, release NOx at lower temperatures. We, therefore, performed PNA cycles on hydrothermally aged Pd/FER materials similar to those discussed in Fig 1B. However, in this case we heated the sample only to $420^{\circ} \mathrm{C}$ in each cycle (instead of the common $500^{\circ} \mathrm{C}$ ) simulating transient FTP (Fig 4 A) before returning to the initial adsorption temperature.

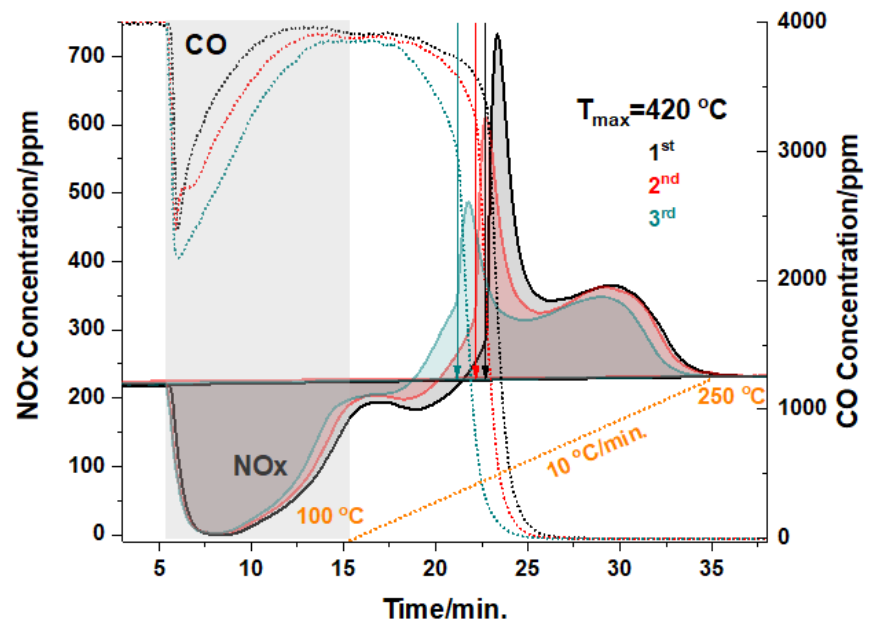

be performed both in the presence and absence of $\mathrm{CO}$ (or lower levels of $\mathrm{CO}$ ) in the gas stream. Moreover, even for $\mathrm{CO}$ oxidation activity tests that utilize high amounts of $\mathrm{CO}$, the light-off curves may not represent the intrinsic activity of the materials, and better (or worse) performance may be caused by nano-scale "hot spots". It is important to note that $\mathrm{CO}$ conversion profiles for this $\mathrm{Pd} / \mathrm{FER}$ material allows for $90 \%$ conversion of $\mathrm{CO}$ at temperatures $\sim 175$ $200^{\circ} \mathrm{C}$ under practically relevant GHSV and gas mixtures. The increase in $\mathrm{CO}$ oxidation activity accompanied by a slight decrease in the NOx storage capacity in repeated cycles can be explained by changes to the speciation of Pd. Nanoscale "hot spots" not only lead to lower-temperature release of $\mathrm{NO}_{\mathrm{x}}$ from $\mathrm{Pd}$ sites but the temperatures achieved drive the $\mathrm{Pd}$ reduction and agglomeration (especially in the presence of $\mathrm{CO}$ and $\mathrm{H}_{2} \mathrm{O}$ ) [12].

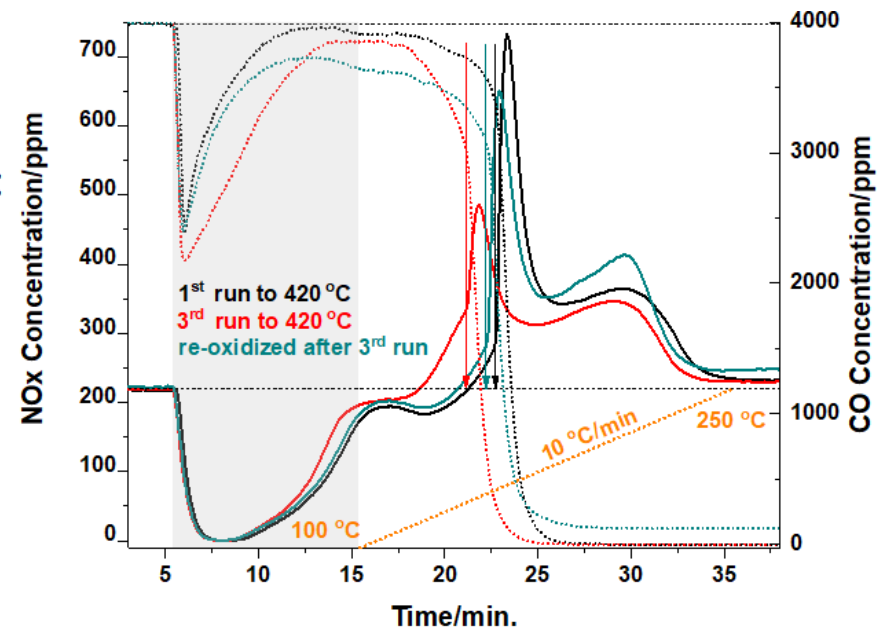

Figure 4. A. PNA performance for 3 consecutive cycles for 1.8 wt $\%$ Pd/FER (HTA). The maximum temperature terminating each cycle is restricted to $420^{\circ} \mathrm{C}$ before cooling to $100^{\circ} \mathrm{C}$ and initiating the subsequent PNA measurements. B. Comparison of PNA performance in the 1st and 3rd cycles with a maximum tempreature of $420^{\circ} \mathrm{C}$, and for the sample reoxidized after the $3 r d$ cycle in the presence of air at $700^{\circ} \mathrm{C}$

As the results in Fig. 4 demonstrate, the quantity of adsorbed/released NO slightly changes after each cycle. The most striking feature, however, is the continuous shift in the initial NOx release temperature to lower values after each cycle. Fig. 4 also exhibits the concentration profiles of $\mathrm{CO}$ during the consecutive NOx uptake/release cycles. Strikingly, the shift of the NOx release profile to lower temperatures perfectly follows the downward shift in the onset temperature of $\mathrm{CO}$ oxidation. These results directly prove that the initial sharp $\mathrm{NO}_{\mathrm{x}}$ release is coupled to $\mathrm{CO}$ oxidation in these materials. During $\mathrm{CO}$ oxidation, even at concentrations as low as $\sim 1,000 \mathrm{ppm}$, local heating drives NOx off the adsorption sites. Simultaneously, a small number of isolated $\mathrm{Pd}$ sites gets reduced. This is the first observation of such local overheating caused by the heat of a reaction (here $\mathrm{CO}$ oxidation) benefiting the desorption profile of PNA materials and has very important implications for regular vehicle catalyst testing protocols. In many of the protocols and published studies [32], high amounts of $\mathrm{CO}$ (up to a few percent) are added to hydrocarbon oxidation streams and the performance of the catalysts is evaluated in the presence of such high $\mathrm{CO}$ amounts. Nano-"hot spots" from the local heat of $\mathrm{CO}$ oxidation (such hot spots are not easily picked-up by thermocouples) may affect the hydrocarbon oxidation profile and shift the conversion to lower temperatures, obscuring the real activity of the material (they would also affect water desorption, etc). In order to avoid potential ambiguity, evaluation of these oxidation catalysts should
Since it is well known that $\mathrm{Pd} / \mathrm{PdO}$ nanoparticles are much more active for CO oxidation than isolated Pd ions (especially on nonreducible supports) [28], the reduction of small amounts of $\mathrm{Pd}$ lead to removal of ionically dispersed $\mathrm{Pd}$ (active for $P N A$ ) and formation of nanoparticles (active for CO oxidation). However, the performance of PNA materials can be fully restored by heating to higher temperatures (condition typically encountered by periodic regeneration of DPF) that result in redispersion of the PdOx/Pd nanoparticles (Fig 4B).

\section{Conclusion}

In summary, we reveal the complex chemistry that occurs during PNA on single-atom Pd zeolite (SSZ-13 and FER) catalysts under practically relevant exhaust gas feeds. We provide deeper insight into the mechanisms of PNA storage, stability, and deactivation of $\mathrm{Pd} /$ zeolite materials as well as $\mathrm{CO}$ oxidation behavior during cold start. Notably, we discovered that thermal migration of $\mathrm{Pd}$ ions into specific positions in FER micropores produces a $\mathrm{Pd}(\mathrm{II}) / 2 \mathrm{Al}$ that is very resistant to hydrothermal aging up to $800^{\circ} \mathrm{C}$ in the presence of $10 \% \mathrm{H}_{2} \mathrm{O}$. Remarkably, at temperatures relevant to cold-start in the presence of $\mathrm{CO}$ in the gas-feed, $\mathrm{CO}$ facilitates $\mathrm{Pd}$ movement into positions which are accessible to $\mathrm{NO}_{\mathrm{x}}$ and enables $\mathrm{NO}_{x}$ storage on such $\mathrm{Pd}(\mathrm{II})$ atoms. We observed the most hydrothermally stable and active $\sim 2 \mathrm{wt} \% \mathrm{Pd} / \mathrm{FER}$ material in 
which the majority of expensive Pd is atomically dispersed and available to NOx storage and which shows excellent performance under repeated cycling.

\section{Acknowledgements}

The research at PNNL was supported by the U.S. Department of Energy, Energy Efficiency and Renewable Energy, Vehicle Technology Office. Experiments were conducted in the Environmental Molecular Sciences Laboratory (EMSL), a national scientific user facility sponsored by the Department of Energy's Office of Biological and Environmental Research at Pacific Northwest National Laboratory (PNNL). PNNL is a multiprogram national laboratory operated for the DOE by Battelle Memorial Institute under Contract DE-AC06-76RL01830. We acknowledge the support of CLEERS (Crosscut Lean Exhaust Emissions Reduction Simulations). CLEERS is an initiative funded by the U.S. Department of Energy (DOE) Vehicle Technologies Office to support the development of accurate tools for use in the design, calibration, and control of next generation engine/emissions control systems that maximize efficiency while complying with emissions regulations.

\section{*Corresponding authors.}

\& These authors contributed equally.

\section{Conflict of interest}

No conflicts to declare.

Keywords: Pd/FER; Passive NOx Adsorbers; NOx uptake/release cycling

(1) Wang, A.; Olsson, L. The Impact of Automotive Catalysis on the United Nations Sustainable Development Goals. Nat. Catal. 2019 2, 566-570.

(2) Royal College of Paediatrics and Child Health . Every breath we take-the lifelong impact of air pollution. London: Royal College of Paediatrics and Child Health, 2016.

(3) N. R. Jaegers, J. K. Lai, Y. He, E. Walter, D. A. Dixon, M. Vasiliu, Y. Chen, C. M. Wang, M. Y. Hu, K. T. Mueller, I. E. Wachs, Y. Wang and J. Z. Hu, Angew. Chem., Int. Ed., 2019, 131, 12739-12746.

(4) Ja-Hun Kwak, Russell G Tonkyn, Do Heui Kim, János Szanyi, Charles HF Peden, J. Catal., 2010, 275, 187-190.

(5) I. Bull, A. Moini, G. Koermer, J. Patchett, W. Jaglowski, S. Roth, US Patent US20070134146A1, 2010.

(6) Chen, H.-Y.; Collier, J. E.; Liu, D.; Mantarosie, L.; Durán- Martín, D.; Novák, V.; Rajaram, R. R.; Thompsett, D. Catal. Lett. 2016, 146 (9), 1706-1711.

(7) Khivantsev, K.; Jaegers, N. R.; Kovarik, L.; Hanson, J. C.; Tao, F. (Feng); Tang, Y.; Zhang, X.; Koleva, I. Z.; Aleksandrov, H. A.; Vayssilov, G. N.; Wang, Y.; Gao, F.; Szanyi, J. Angew. Chem. 2018, 130 (51), 16914-16919.

(8) Khivantsev, K.; Jaegers, N. R.; Kovarik, L.; Prodinger, S.; Derewinski, M. A.; Wang, Y.; Gao, F.; Szanyi, J. Appl. Catal. A Gen. 2019, 569, 141-148.

(9) Khivantsev, K.; Jaegers, N. R.; Koleva, I. Z.; Aleksandrov, H. A. Kovarik, L.; Engelhard, M.; Gao, F.; Wang, Y.; Vayssilov, G. N.; Szanyi, J. J. Phys. Chem. C 2020, 124 (1), 309-321.
(10) Khivantsev, K.; Gao, F.; Kovarik, L.; Wang, Y.; Szanyi, J. J. Phys Chem. C 2018, 122 (20), 10820-10827.

(11) Moliner, M.; Corma, A. React. Chem. Eng. 2019, 4 (2), 223-234.

(12) Khivantsev, K.; Jaegers, N. R.; Kovarik, L.; Hu, J. Z.; Gao, F.; Wang, Y.; Szanyi, J. Emiss. Control Sci. Technol. 2019. DOI: 10.1007/s40825-019-00139-w

(13) E. Bello, V. J. Margarit, E. M. Gallego, F. Schuetze, C. Hengst , A Corma, M. Moliner, Microporous and Mesoporous Materials 302 (2020) 110222.

(14) K. Khivantsev, N. R. Jaegers, L. Kovarik, M. Wang, J. Z. Hu, M. Derewinski, J. Szanyi, Chemrxiv 2020 DOI: 10.26434/chemrxiv.11821347

(15) Rajaram, R. R., Chen, H.-Y., Liu, D., US Patent US20150158019A1, 2015

(16) Y. Ji, S. Bai and M. Crocker , Appl. Catal., B, 2015, 107-171 , 283292.

(17) O. Mihai, L. Trandafilović, T. Wentworth, F.F. Torres, L. Olsson, Top. Catal., 61 (2018), pp. 2007-2020.

(18) R. Jonsson, J. Woo, M. Skoglund, L. Olsson, Catalysts 2020, 10(2), 173; https://doi.org/10.3390/catal10020173

(19) Ji, Y.; Xu, D.; Bai, S.; Graham, U.; Crocker, M.; Chen, B.; Shi, C.; Harris, D.; Scapens, D.; Darab, J. Ind. Eng. Chem. Res. 2017, 56, 111-125.

(20) K Khivantsev, J Szanyi, NR Jaegers, L Kovarik, F Gao, Y Wang, US Patent App. 16/546,641

(21) L. Castoldi, R. Matarrese, S. Morandi, P. Ticali, Luca Lietti, Catal. Today 2020 doi.org/10.1016/j.cattod.2020.02.019

(22) A. Porta, T. Pellegrinelli, L. Castoldi, R. Matarrese, S. Morandi, S Dzwigaj, L. Lietti, Top. Catal. 61 (2018) 2021-2034.

(23) Y. Ji, S. Bai, D. Xu, D. Qian, Z. Wu, Y. Song, R. Pace, M. Crocker K. Wilson, A. Lee, D. Harris, D. Scapens, App. Cat. B. 2019 doi: https://doi.org/10.1016/j.apcatb.2019.118499

(24) Ryou, Y. S.; Lee, J.; Cho, S. J.; Lee, H.; Kim, C. H.; Kim, D. Appl. Catal. B Environ. 2017, 212, 140-149.

(25) Ryou, Y. S.; Lee, J.; Lee, H.; Kim, C. H.; Kim, D. H., Catal. Today 2019, 320, 175-180.

(26) Lee, J.; Ryou, Y.; Hwang, S.; Kim, Y.; Cho, S. J.; Lee, H.; Kim, C H.; Kim, D. H., Catal. Sci. Technol. 2019, 9 (1), 163-173.

(27) Kim, Y.; Hwang, S.; Lee, J.; Ryou, Y. S.; Lee, H.; Kim, C. H.; Kim, D. H. Emiss. Control Sci. Technol. 2019, 5 (2), 172-182.

(28) Pereira-Hernandez, X. I.; DelaRiva, A.; Kunwar, D.; Xiong, H.; Sudduth, B.; Engelhard, M.; Kovarik, L.; Murayev, V.; Hensen, E.; Wang, Y.; Datye, A. K. Nat. Commun. 2019, DOI: 10.1038/s41467019-09308-5

(29) T. Seiyama, T. Arakawa, T. Matsuda, N. Yamazoe, and Y. Takita Chem. Lett., 781 (1975)

(30) Zones, S.I. US Patent 4544 538, 1985.

(31) M. C. Dalconi, A. Alberti, G. Cruciani, J. Phys. Chem. B 2003, 107 12973-12980

(32) Rappé, K.G. et al. Emiss. Control Sci. Technol. 6, 1-32 (2019) 


\section{Pd/FER vs Pd/SSZ-13 Passive NOx Adsorbers: Adsorbate-controlled Location of Atomically Dispersed Pd(II) in FER Determines High Activity and Stability}

Konstantin Khivantsev, ${ }^{a *}$ Xinyi Wei, ${ }^{b^{*}}$ Libor Kovarik, ${ }^{a}$ Nicholas R. Jaegers, ${ }^{a}$ Eric D. Walter, ${ }^{a}$ Pascaline Tran, ${ }^{\mathrm{b}}$ Yong Wang ${ }^{\mathrm{a}, \mathrm{c}}$ and Janos Szanyji*

\section{Supplementary Information}

\section{Materials and Methods}

$\mathrm{NH}_{4}$-form of FER zeolite with Si/AI 10 was supplied by BASF.

$\mathrm{Na}$ /SSZ-13 zeolite with Si/AI $\sim 6$ and 10-12 was hydrothermally synthesized using the following recipe: $0.8 \mathrm{~g}$ of $\mathrm{NaOH}$ (Sigma Aldrich, $\geq 99 \%$ ) was dissolved in $50 \mathrm{ml}$ of deionized water. Then, $17 \mathrm{~g}$ of TMAda-OH (Sachem Inc., 25\% N,N,N-trimethyl-1-adamantyl ammonium hydroxide) was added as structure directing agent. Consequently, 1.5 or $0.75 \mathrm{~g}$ of $\mathrm{Al}(\mathrm{OH})_{3}$ (Sigma Aldrich, $\sim 54 \% \mathrm{Al}_{2} \mathrm{O}_{3}$ ) was slowly added to the solution and stirred at $400 \mathrm{rpm}$ until it was completely dissolved. Afterwards, $20.0 \mathrm{~g}$ of LUDOX HS-30 colloidal silica (Sigma Aldrich, 30 wt\% suspension in $\mathrm{H}_{2} \mathrm{O}$ ) was added slowly to the solution until a uniform white gel was formed. The obtained gel was sealed in a $125 \mathrm{~mL}$ Teflon-lined stainless steel autoclave containing a magnetic stir bar. Hydrothermal synthesis was carried out at $160^{\circ} \mathrm{C}$ under continuous gel stirring at $400 \mathrm{rpm}$ for 4 days. After synthesis, the zeolite cake was separated from the suspension by centrifugation and washed thoroughly with deionized water. It was then dried at $80^{\circ} \mathrm{C}$ under $\mathrm{N}_{2}$ flow overnight and calcined in air at $550^{\circ} \mathrm{C}$ for $5 \mathrm{~h}$ in order to remove the SDA. $\mathrm{NH}_{4} / \mathrm{SSZ}-13$ was obtained by ion exchange of the as-prepared Na/SSZ-13 zeolite with $0.5 \mathrm{M} \mathrm{NH}_{4} \mathrm{NO}_{3}$ solution at $80^{\circ} \mathrm{C}$ for $5 \mathrm{~h}$. The process was repeated three times.

$\mathrm{Pd} /$ Zeolite powders with desired loading of $\mathrm{Pd}(1$ and $1.8 \mathrm{wt} \%)$ were obtained via modified incipient wetness impregnation method, described by us earlier, with $\mathrm{Pd}(\mathrm{II})$ tetramine nitrate solution (10 wt \%, Sigma) and $\mathrm{NH}_{4}$-forms of zeolites. Benefits of using palladium (II) tetra-amine nitrate precursor versus palladium nitrate as well as $\mathrm{NH}_{4}$-forms of zeolite were previously described in detail $[10,11,17]$. They were subsequently dried at $80^{\circ} \mathrm{C}$ and subsequently calcined at $600^{\circ} \mathrm{C}$ in static air. More specifically a minimum amount of the $\mathrm{Pd}(\mathrm{II})$ precursor solution was added to zeolite in the amount approximately equivalent to the total pore volume of the zeolite. The thick paste was mixed for 30 minutes, followed by calcination in air at $550^{\circ} \mathrm{C}$ for $5 \mathrm{~h}$ (ramping rate $\left.2^{\circ} \mathrm{C} / \mathrm{min}\right)$.

Hydrothermal aging (HTA) was performed at $800^{\circ} \mathrm{C}$ for 16 hours in a flow reactor with GHSV $150 \mathrm{~L} / \mathrm{g}^{\star} \mathrm{hr}$. The gas mix, used for HTA, containing air and $10 \% \mathrm{H}_{2} \mathrm{O}$ in air. 
Heating in technical air was performed at $800 \mathrm{C}$ for $\sim 2$ hours to enable Pd migration and redistribution in the micropores.

The in situ transmission IR experiments were conducted in a home-built cell housed in the sample compartment of a Bruker Vertex 80 spectrometer, equipped with an MCT detector and operated at $4 \mathrm{~cm}^{-1}$ resolution. The powder sample was pressed onto a tungsten mesh which, in turn, was mounted onto a copper heating assembly attached to a ceramic feedthrough. The sample could be resistively heated, and the sample temperature was monitored by a thermocouple spot welded onto the top center of the $\mathrm{W}$ grid. The cold finger on the glass bulb containing $\mathrm{CO}$ was cooled with liquid nitrogen to eliminate any contamination originating from metal carbonyls, while NO was cleaned with multiple freeze-pump-thaw cycles. Prior to spectrum collection, a background with the activated (annealed, reduced or oxidized) sample in the IR beam was collected. Each spectrum reported is obtained by averaging 64 scans.

HAADF-STEM analysis was performed with a FEI Titan 80-300 microscope operated at 300 $\mathrm{kV}$. The instrument is equipped with a CEOS $\mathrm{GmbH}$ double-hexapole aberration corrector for the probe-forming lens, which allows for imaging with $0.1 \mathrm{~nm}$ resolution in scanning transmission electron microscopy mode (STEM). The images were acquired with a high angle annular dark field (HAADF) detector with inner collection angle set to $52 \mathrm{mrad}$.

Standard NOx adsorption tests were conducted in a plug-flow reactor system with powder samples (120 mg, 60-80 mesh) loaded in a quartz tube, using a synthetic gas mixture that contained $\sim 200-220$ ppm of NOx, varying amounts of CO (200-250 ppm, 1,200 ppm or 4,000 ppm), $14 \% \mathrm{O}_{2}, 3 \% \mathrm{H}_{2} \mathrm{O}$ balanced with $\mathrm{N}_{2}$ at a flow rate of $300 \mathrm{sccm}$. All the gas lines were heated to over $100{ }^{\circ} \mathrm{C}$. Concentrations of reactants and products were measured by an online MKS MultiGas 2030 FTIR gas analyzer with a gas cell maintained at $191^{\circ} \mathrm{C}$. GHSV for all the adsorption/desorption experiments was $150 \mathrm{~L} / \mathrm{g} * \mathrm{hr}$.

In-situ electron paramagnetic resonance (EPR) experiments were carried out on a Bruker E580 X-band spectrometer. Powder samples $(\sim 25 \mathrm{mg})$ were placed in $4 \mathrm{~mm}$ OD quartz tubes open on both ends and the powder was held by quartz wool. Gases (1\% CO in nitrogen, 1\% NO in nitrogen, Air) were used. 


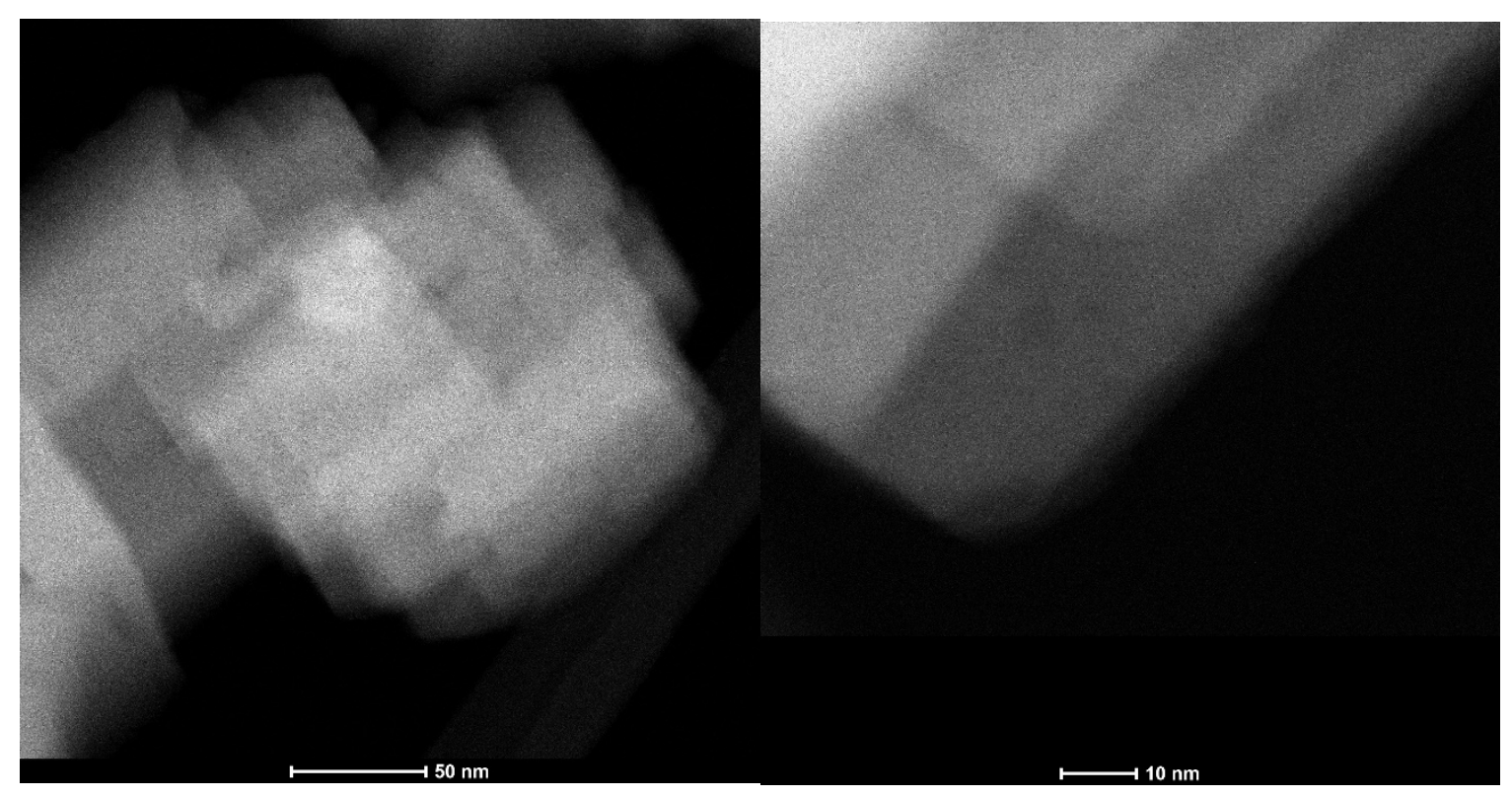

Figure S1. HAADF-STEM images of 1 wt $\% \mathrm{Pd} / \mathrm{SSZ}-13$ with Si/Al $\sim 6$. 


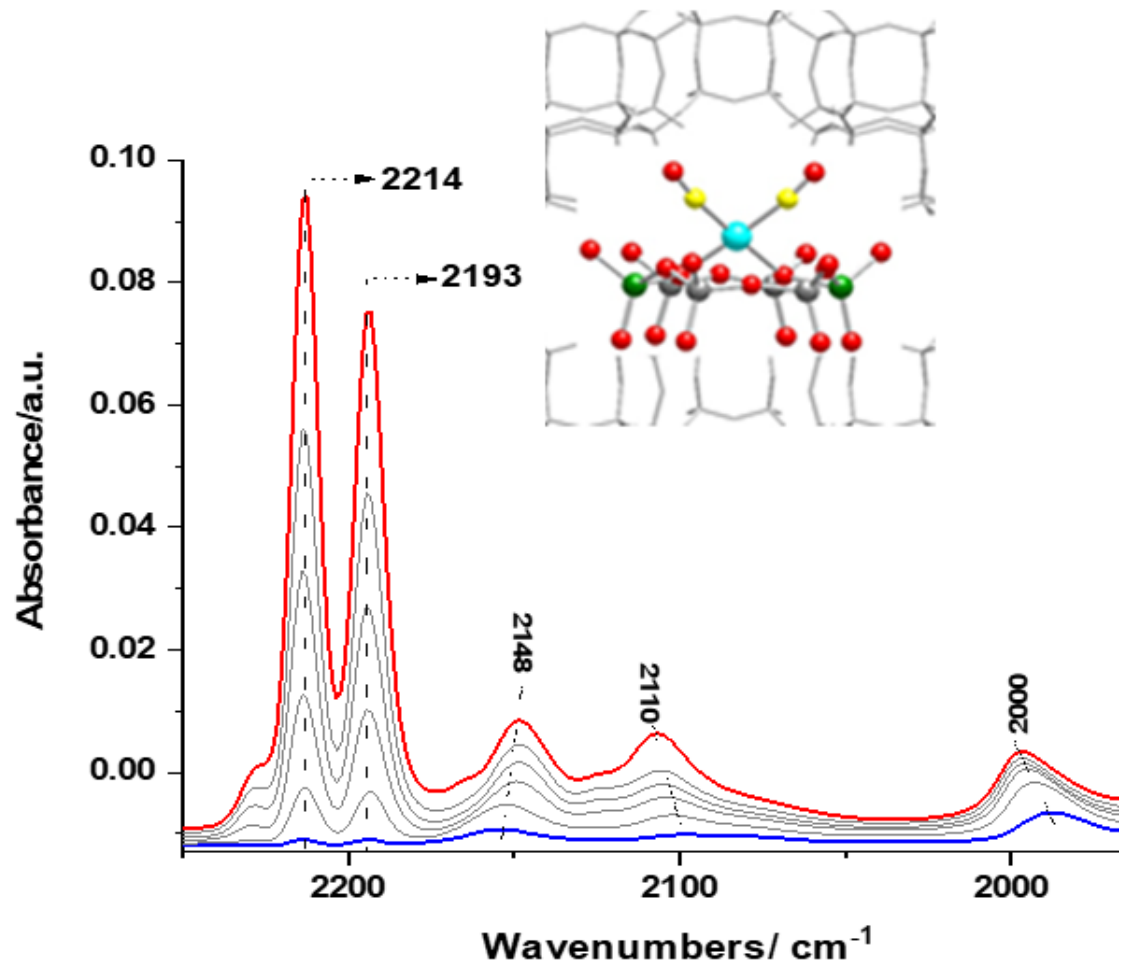

Figure S2. FTIR during CO adsorption on 1 wt\% Pd/SSZ-13 with Si/AI $\sim 6$. The sample contains the majority $(>95 \%)$ of $\mathrm{Pd}(\mathrm{II}) / 2 \mathrm{Al}$ sites. 


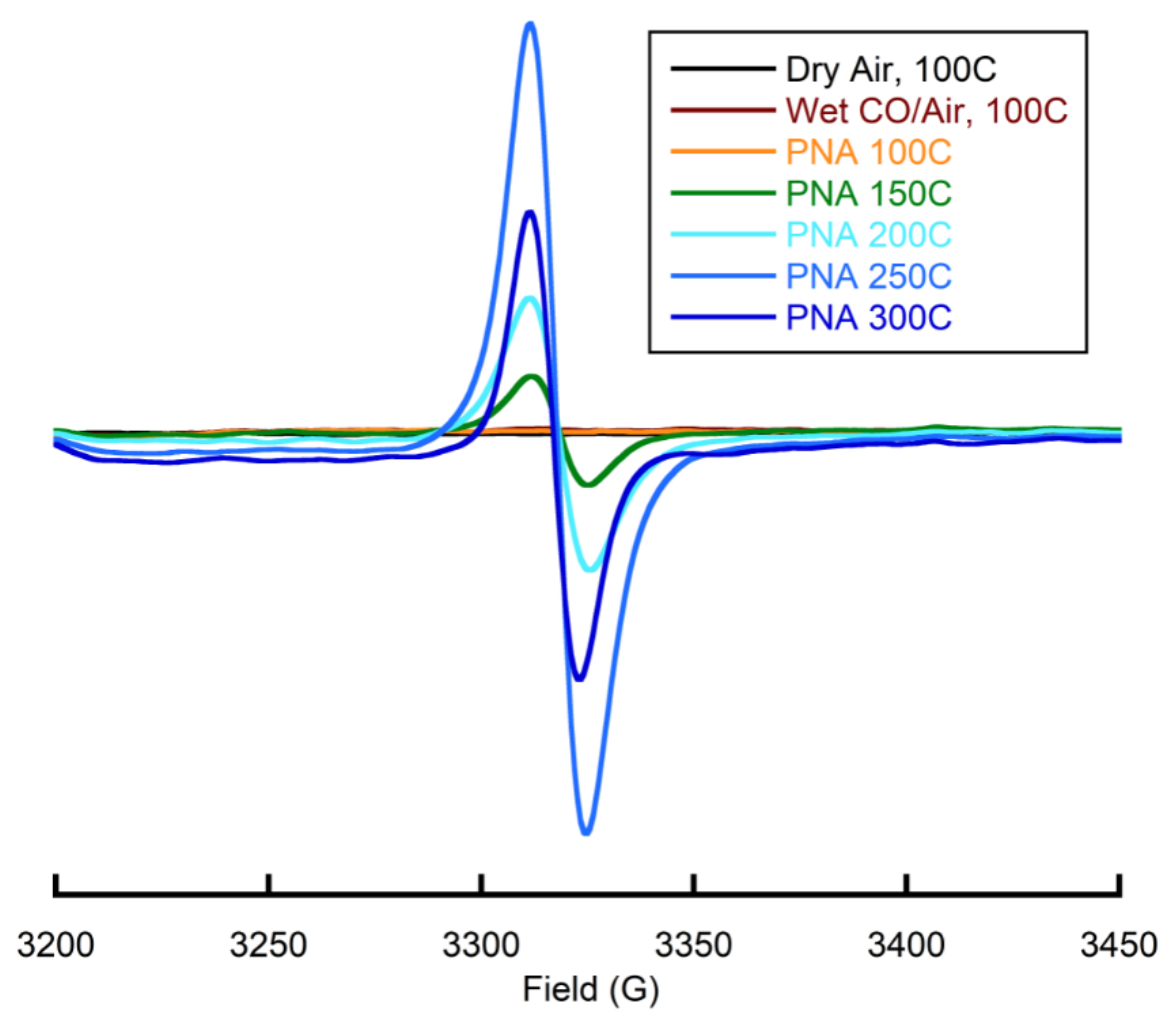

Figure S3. In-situ EPR studies with $1 \mathrm{wt} \% \mathrm{Pd} / \mathrm{SSZ}-13$ with Si/Al $\sim 6.25 \mathrm{mg}$ of the sample was put in the flow-through quartz reactor positioned inside the EPR magnet. First, the sample was treated in dry air at $100^{\circ} \mathrm{C}$. A gas stream of $\sim 500 \mathrm{ppm} N \mathrm{NO}, 1,000$ ppm CO, $\sim 3 \%$ water, $14 \% \mathrm{O}_{2}$ in $\mathrm{N}_{2}$ was initiated starting at $100^{\circ} \mathrm{C}$ and GHSV $\sim 175$ $\mathrm{L} / \mathrm{g}^{*} \mathrm{hr}$ and allowed to equilibrate at each temperature (approx $\sim 15-20$ minutes). No formation of $\mathrm{Pd}(\mathrm{I}), \mathrm{Pd}(\mathrm{III})$ was detected at the temperature of the experiment as well as upon cooling to liquid nitrogen temperature after the experiment. $\mathrm{Pd}(0)$ was absent in measurable amounts as well within the sensitivity of the experiments (characterized by broad bands). We note the formation of some radical species starting at $150^{\circ} \mathrm{C}$, evidenced from the spectra. This radical species concentration, however, was very small - the maximum level observed was on the order of $\sim 10-20 \mathrm{ppm}$. 


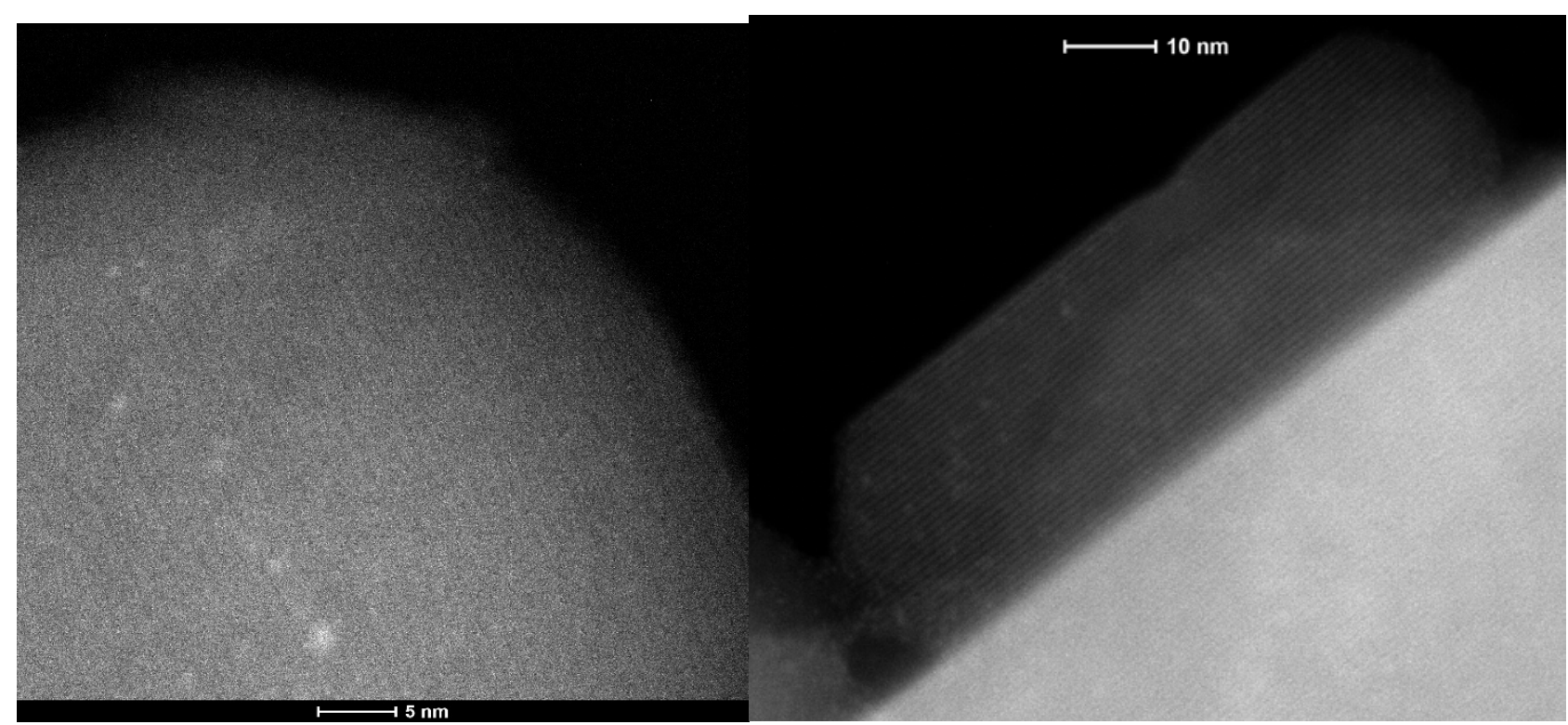

Figure S4. Additional HAADF-STEM images of $1.8 \mathrm{wt} \% \mathrm{Pd} / \mathrm{FER}$, showing presence of subnanometer ( $<0.9 \mathrm{~nm}$ on average) PdOx clusters decorating the external surfaces of FER crystals. This is analogous to Pd/SSZ-13 with Si/Al 10-12 (Fig. S5). 

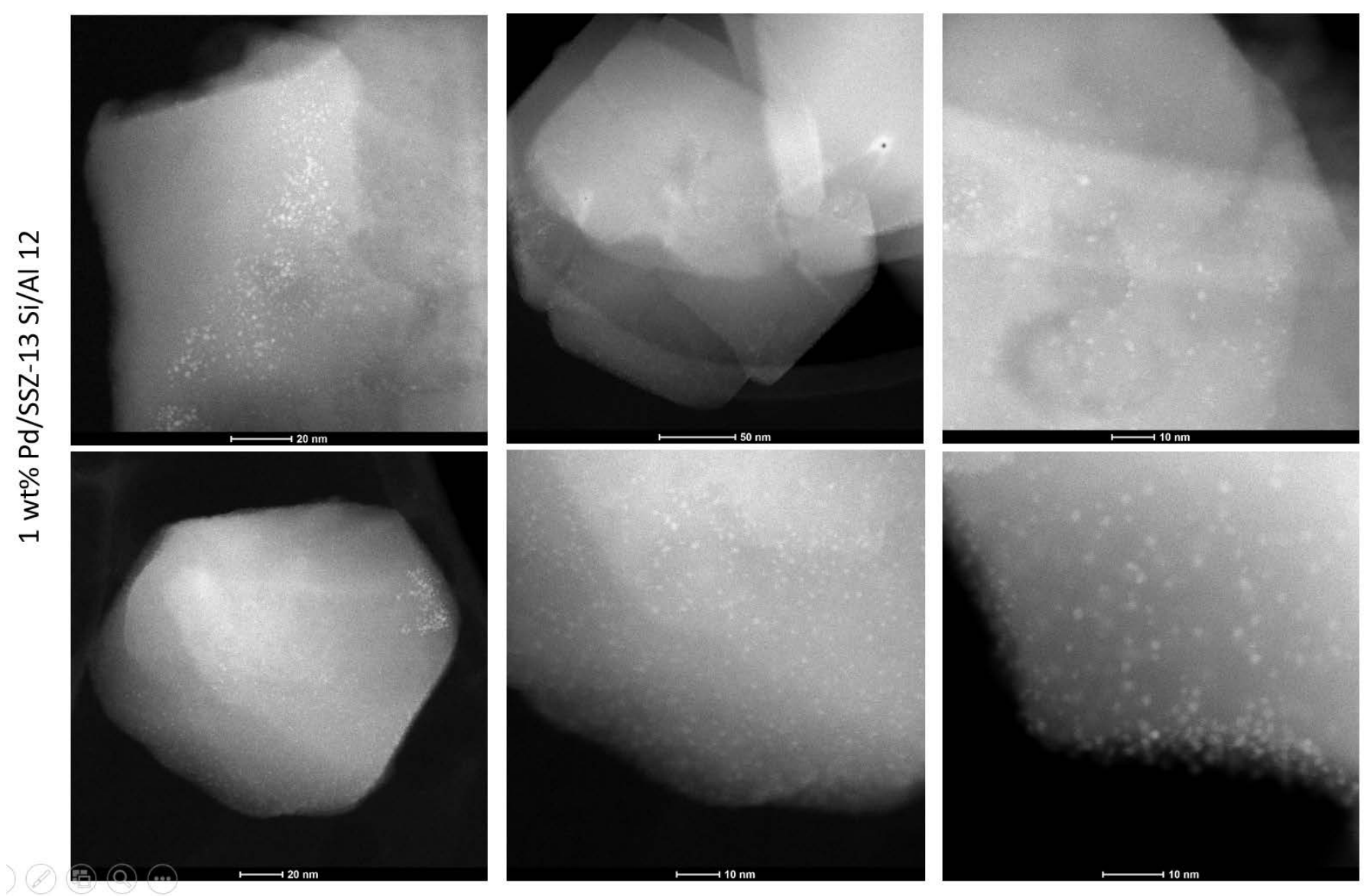

Figure S5. HAADF-STEM images of 1 wt $\%$ Pd/SSZ-13 with Si/AI 10-12.

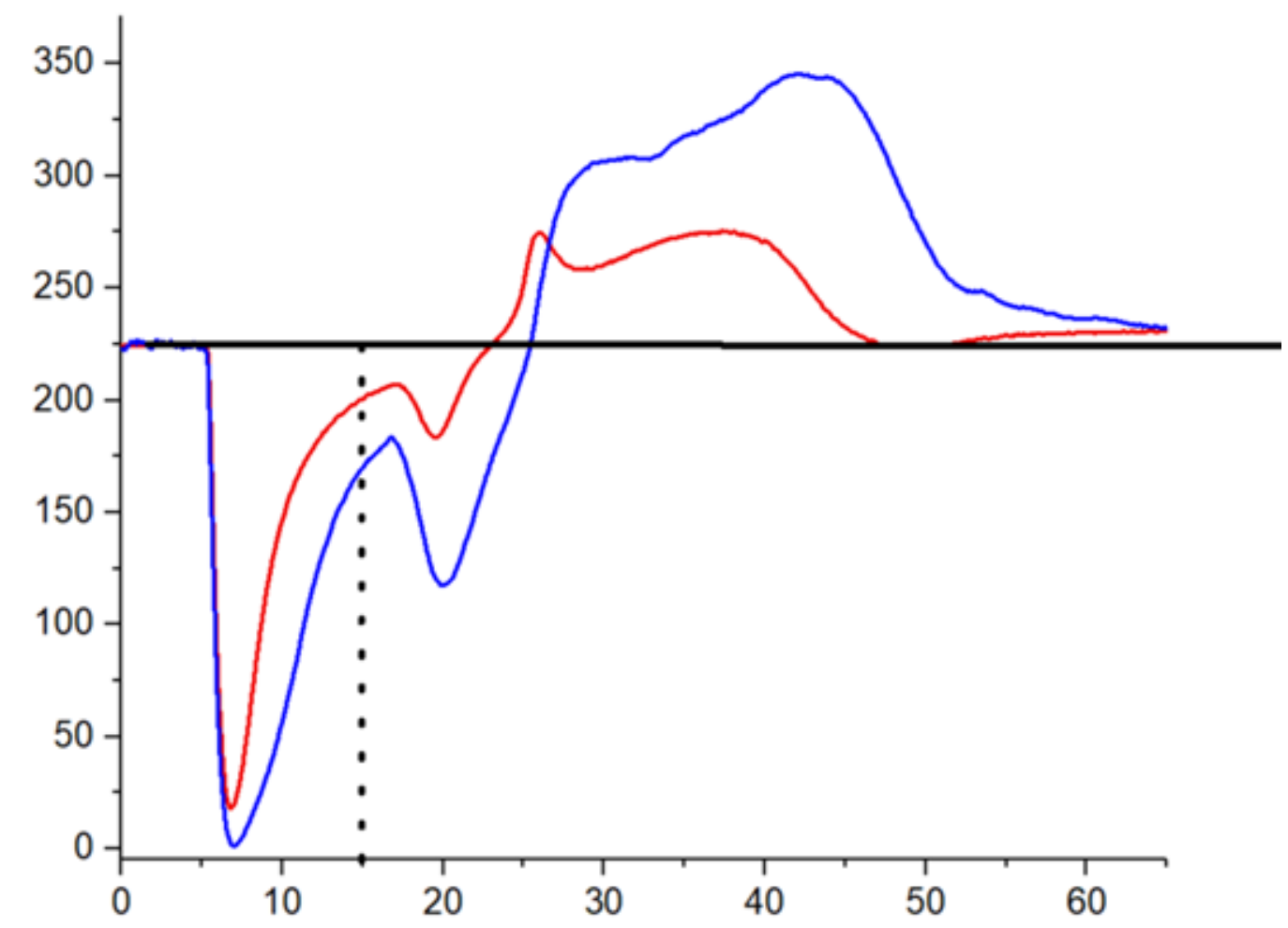


Figure S6. NOx adsorption and desorption profile for fresh $1.8 \mathrm{wt} \% \mathrm{Pd} / \mathrm{FER}$ samples calcined at $500^{\circ} \mathrm{C}$ (red) and $800^{\circ} \mathrm{C}$ (blue) in the presence of $\sim 220 \mathrm{ppm} \mathrm{NOx,} \sim 250 \mathrm{ppm}$ $\mathrm{CO}, 14 \% \mathrm{O}_{2}, 3 \% \mathrm{H}_{2} \mathrm{O}$, and $\mathrm{N}_{2}$. Thermal desorption was started at 15 min mark. Lowtemperature adsorption was conducted at $100^{\circ} \mathrm{C}$. GHSV was $150 \mathrm{~L} / \mathrm{g}^{*} \mathrm{hr}$.

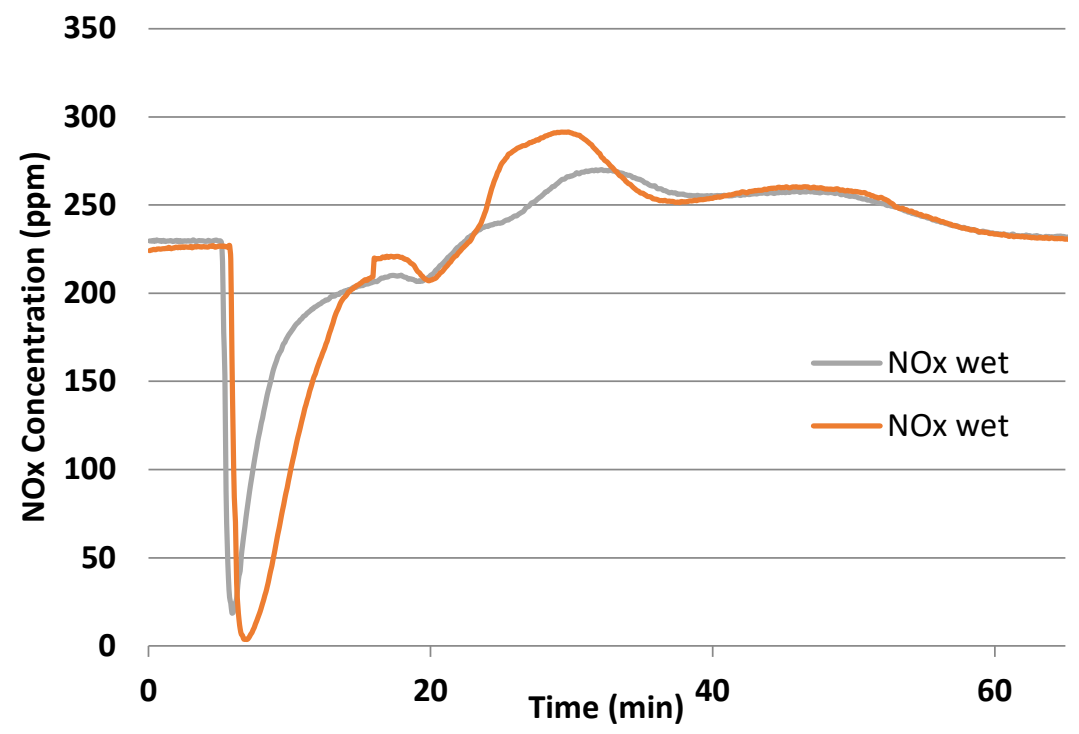

Figure S7. NOx adsorption and desorption profiles for $1 \mathrm{wt} \% \mathrm{Pd} / \mathrm{FER}$ (calcined at $800^{\circ} \mathrm{C}$ ) with Si/Al $\sim 10$ in the presence of $200 \mathrm{ppm} \mathrm{CO}$ (gray) and 1,000 ppm CO

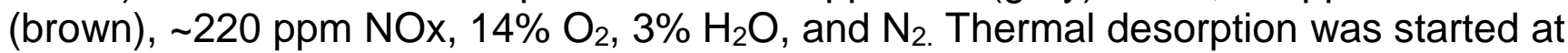
15 min mark. Low-temperature adsorption was conducted at $100^{\circ} \mathrm{C}$. GHSV was 150 L/g*hr. 


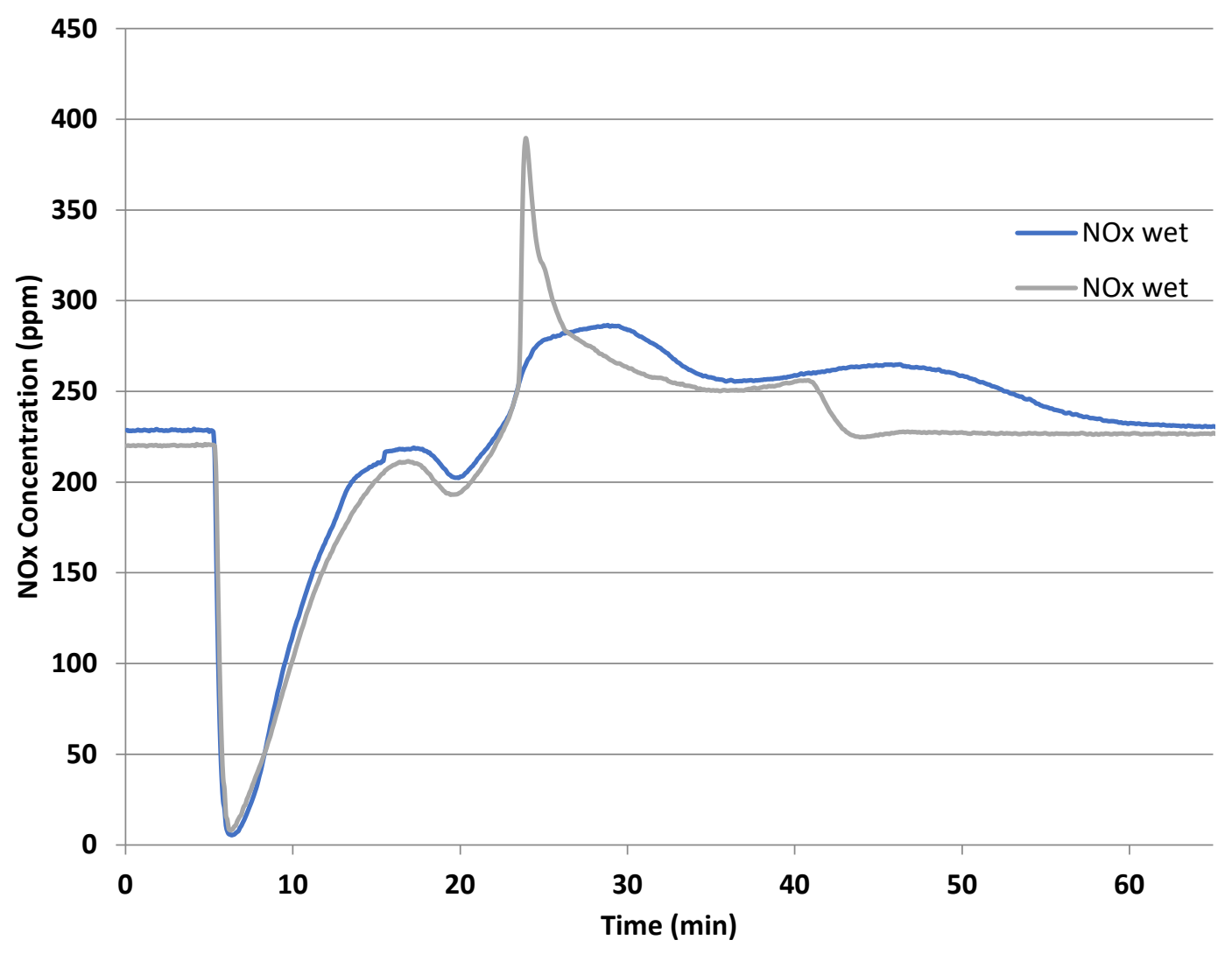

Figure S8. NOx adsorption and desorption profiles for $1 \mathrm{wt} \% \mathrm{Pd} / \mathrm{FER}$ (calcined at $800^{\circ} \mathrm{C}$ ) with Si/Al $\sim 10$ in the presence of $1,000 \mathrm{ppm} \mathrm{CO}$ (blue) and 4,000 ppm CO (gray), $\sim 220 \mathrm{ppm} \mathrm{NOx}, 14 \% \mathrm{O}_{2}, 3 \% \mathrm{H}_{2} \mathrm{O}$, and $\mathrm{N}_{2}$. Thermal desorption was started at 15 min mark. Low-temperature adsorption was conducted at $100^{\circ} \mathrm{C}$. GHSV was 150 L/g*hr. 


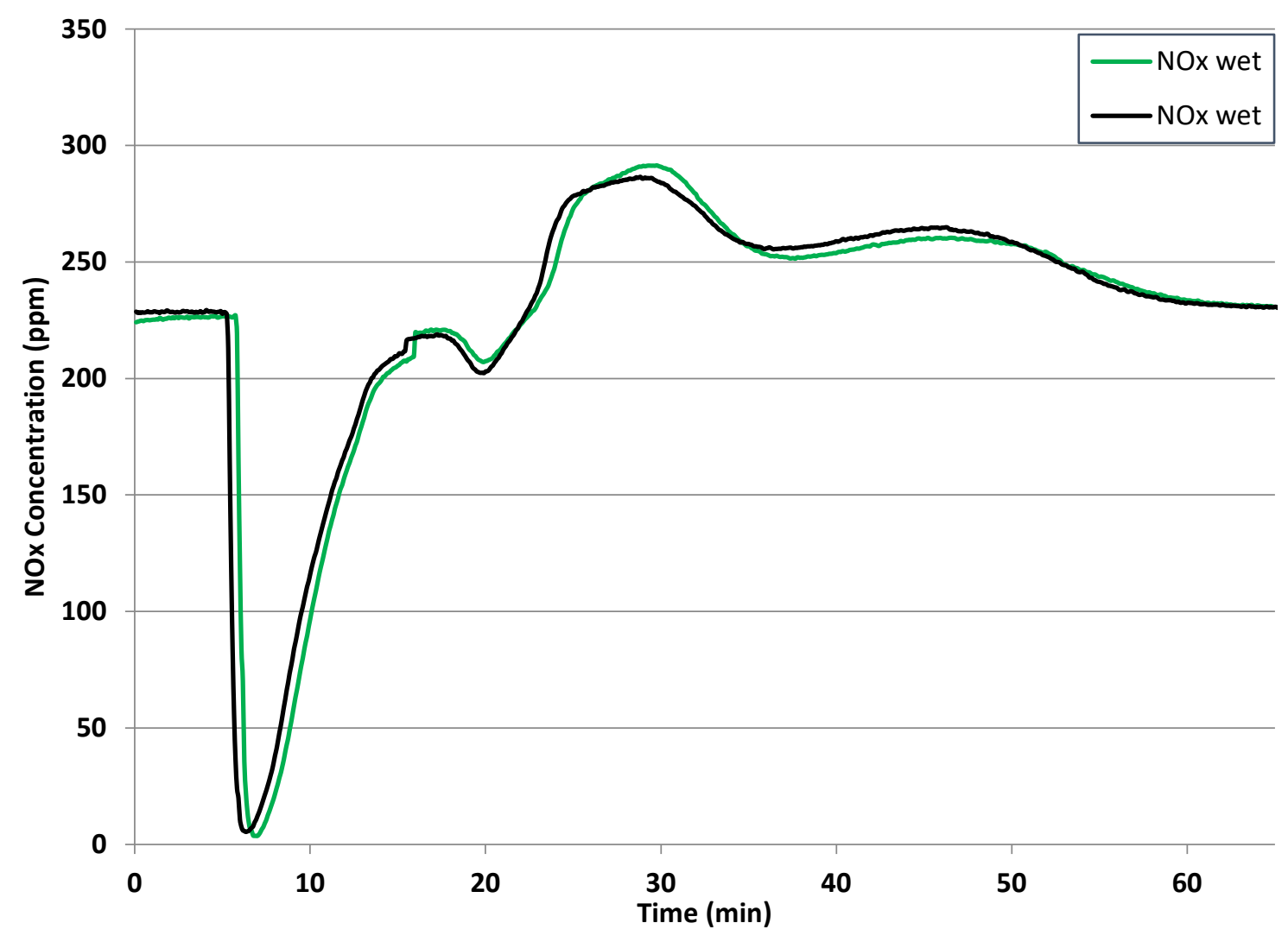

Figure S9. NOx dsorption and desorption profiles for $1 \mathrm{wt} \% \mathrm{Pd} / \mathrm{FER}$ (calcined at $800^{\circ} \mathrm{C}$ ) with $\mathrm{Si} / \mathrm{Al} \sim 10$ in the presence of $1,000 \mathrm{ppm}$ CO tested two times in a row with $\sim 220 \mathrm{ppm} \mathrm{NOx}, 14 \% \mathrm{O}_{2}, 3 \% \mathrm{H}_{2} \mathrm{O}$, and $\mathrm{N}_{2}$. Thermal desorption was started at $15 \mathrm{~min}$ mark. Low-temperature adsorption was conducted at $100^{\circ} \mathrm{C}$. GHSV was $150 \mathrm{~L} / \mathrm{g}^{\star} \mathrm{hr}$. 


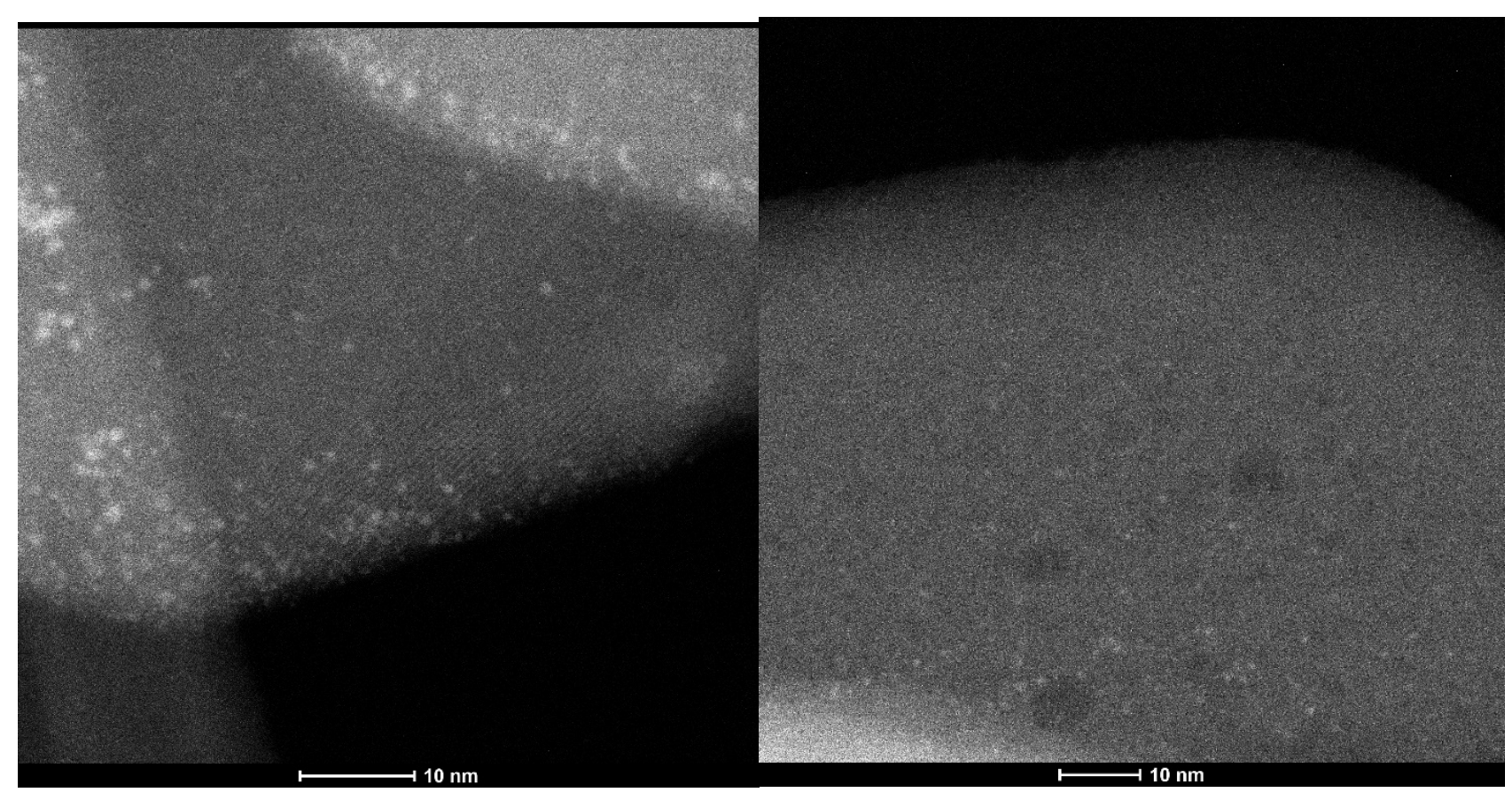

Figure S10. Additional HAADF-STEM images of utilized 1.8 wt\% Pd/FER after lowtemperature $\sim 220 \mathrm{ppm} \mathrm{NO}, \sim 4,000 \mathrm{ppm} \mathrm{CO} \sim 3 \% \mathrm{H} 2 \mathrm{O} \sim 14 \% \mathrm{O} 2$ and $\mathrm{N}_{2}$ gas treatment (GHSV $\sim 150 \mathrm{~L} / \mathrm{g}^{*} \mathrm{hr}$ ) at $100{ }^{\circ} \mathrm{C}$ for 30 minutes. 


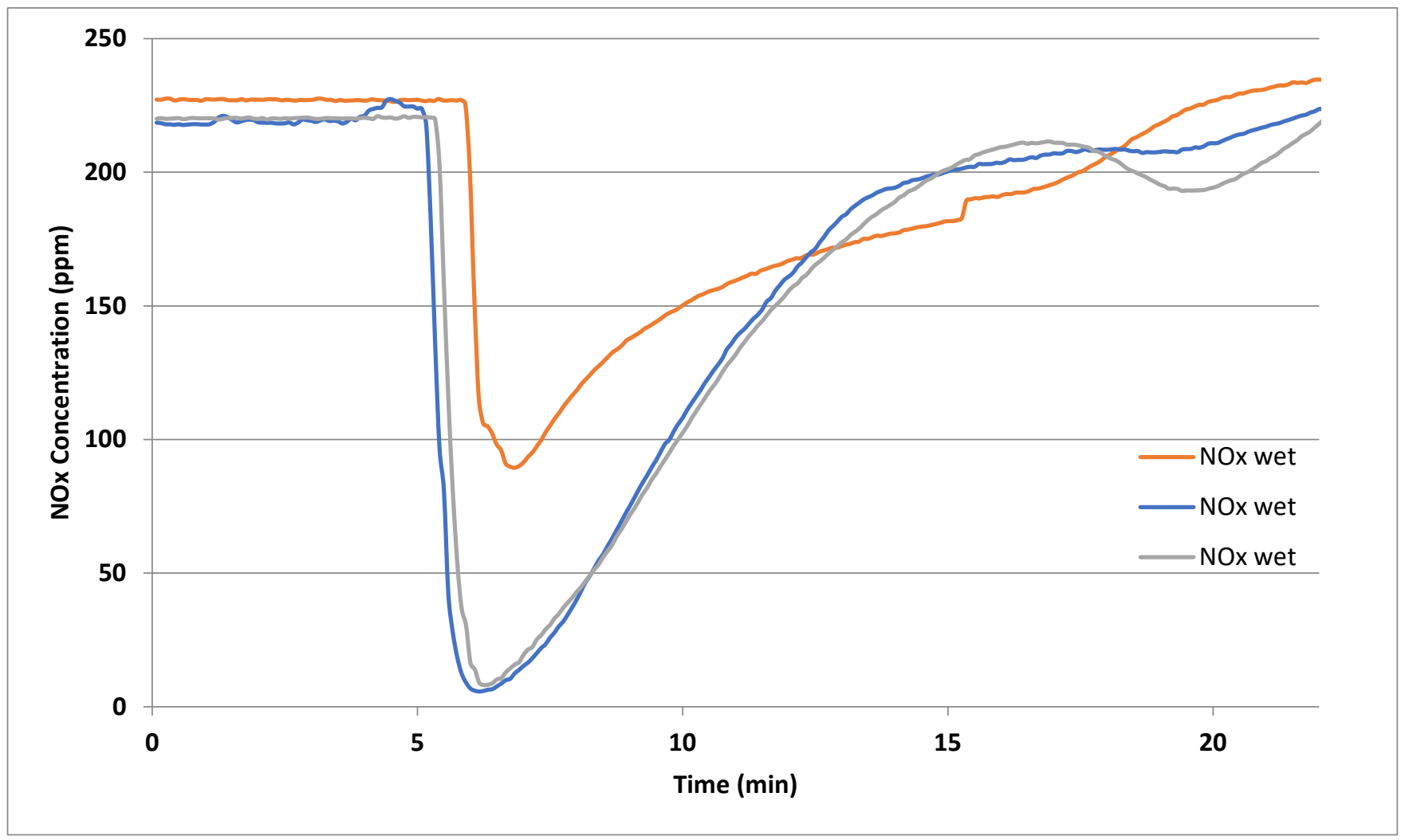

Figure S11. NOx adsorption profiles for freshly $800^{\circ} \mathrm{C}$ calcined $1 \mathrm{wt} \% \mathrm{Pd} / \mathrm{FER}$ (gray), hydrothermally aged for 16 hours at $800^{\circ} \mathrm{C}$ in $10 \% \mathrm{H}_{2} \mathrm{O} /$ air mix sample (blue), and the same sample hydrothermally-aged at $850^{\circ} \mathrm{C}$ in $10 \% \mathrm{H}_{2} \mathrm{O} /$ air mix for 16 hours (orange) -220 ppm NOx, $14 \% \mathrm{O}_{2}, 3 \% \mathrm{H}_{2} \mathrm{O}$, and $\mathrm{N}_{2}$. Low-temperature adsorption was conducted at $100^{\circ} \mathrm{C}$ from 5 until 15 min mark. GHSV was $150 \mathrm{~L} / \mathrm{g}^{\star} \mathrm{hr}$. 